\title{
First report of Kogia sima (Cetacea: Kogiidae) on the Caribbean coast of Honduras
}

\author{
Leonel Marineros ${ }^{1}$, María Eugenia Mondragón ${ }^{2,3}$ and Wilfredo Matamoros ${ }^{2,3,4}$ \\ 1. Monitoring and Research Division, Punta Izopo National Park. PROLANSATE Foundation. PROCORREDOR Project. Bo. El Centro, Tela, Atlántida, \\ Honduras; Imarineros@gmail.com \\ 2. Research Institute - Universidad Pedagógica Nacional Francisco Morazán UPNFM, Honduras \\ 3. Instituto de Ciencias para el Estudio y Conservación de la Biodiversidad (INCEBIO), Honduras \\ 4. Louisiana State University, Museum of Natural Science. 110a Foster Hall, Baton Rouge, LA 70803, USA
}

Received 23-XI-2012 Corrected 12-II-2013 Accepted 21-III-2013

\section{ABSTRACT}

The first report of Kogia sima on the Caribbean coast of Honduras and second in Central America was documented from an individual found stranded in Punto Izopo National Park located in Tela-Atlántida (February 6th 2011). The identification of the individual as $K$. sima was based on a combination of morphological and meristic characteristics.

\section{KEY WORDS}

Dwarf sperm whale, Central America, Honduras, Kogia sima, Punta Izopo National Park

\section{RESUMEN}

Primer reporte de Kogia sima en la costa Caribe de Honduras y el segundo en América Central; se documentó un individuo encallado en el Parque Nacional Punto Izopo situado en Tela, Atlántida (06 de febrero del 2011). La identificación del individuo como K. sima se basa en una combinación de características morfológicas y merísticas.

\section{PALABRAS CLAVE}

Cachalote enano, América Central, Honduras, Kogia sima, Parque Nacional Punta Izopo
Thirty two species of cetaceans are reported to inhabit Central American marine waters (Reid, 1997) from which nine have been reported to occur along Honduras. Most of these reports come from specimens found stranded in the Caribbean coastline or from sightings (Magileviciute, 2007; Marineros \& Martínez-Gallegos, 1998; Bolton, Bolton, Hoggard \& Mullin, 1993; Kuczaj-II \& Yeater, 2007), allowing the possibility that the number of cetaceans that may occur in Honduran waters may be larger than known (Marineros y Martínez-Gallegos, 1998).

The family Kogiidae consists of two cosmopolitan species: the pygmy sperm whale (Kogia breviceps) and the dwarf sperm whale (Kogia sima). Both occur in temperate and tropical pelagic waters. In Middle America the species have been reported in the Gulf of Mexico and the Caribbean Sea (Chivers, Leduc \& Robertson, 2005; Bermudez-Villapol, Sayegh \& León., 2008; Ward, Moscrop \& Carlson, 2001). Because these two species primarily inhabit deep waters, sightings are sporadic and identification cumbersome (Baird, 2005). Specific identification is further hindered by meristic counts and body proportions greatly overlapping between the species (Bermudez-Villapol et al., 2008; Leatherwood \& Hobbs, 1988; Ward et al., 2001) and very little is known about the biologies and natural histories of these species. Due to identification difficulties, records include ambiguous reports and many sightings of these species are reported just as Kogia sp. (Ward et al., 2001).

Even though morphological characters greatly overlap between species, some measurements do allow for differentiation. For example, K. breviceps can be larger and heavier than $K$. sima and has a relatively smaller, morerounded dorsal fin, which is positioned further back than in K. sima. A more accurate identifier is tooth count, with K. breviceps having 12 to 16 pairs of teeth and $K$. sima having just 8 to 13 pairs (Chivers et al., 2005; Reid, 1997; 
Jefferson, Webber \& Pitman, 2008; Leatherwood \& Reeves, 1983; Caldwell \& Caldwell, 1989). Another morphometric criteria used to verify specimens of $K$. sima is to refer to the average obtained when comparing the percentages of the dorsal fin's heights against the total animal's lengths; this value should be higher than $5 \%$ in $K$. sima (Jefferson et al., 1993).

On February 6th 2011, a dying whale was found stranded in the Caribbean coast of Honduras (Fig. 1), near the mouth of the Gamma River located in the Punta Izopo National Park ( $\left.15^{\circ} 48^{\prime} \mathrm{N} 087^{\circ} 23^{\prime} \mathrm{W}\right)$. To identify the specimen the following measurements were taken; total body length, dorsal fin height, and distance from snout to the start of dorsal fin. The specimen was photographed and buried the next day where found. The following combination of characters allowed the identification of the specimen as K. sima (Fig. $2 \mathrm{~A})$ : dorsal fin located midway along the back, presence of 16 teeth in the lower jaw (Fig. 2B), and a value of $8 \%$ when comparing the percentage of the dorsal fin's height $(19 \mathrm{~cm})$ against the total animal's length $(235 \mathrm{~cm})$. The identification of the individual was confirmed by Susan Chivers (National Marine Fishery Service of the National Oceanic and Atmospheric Administration at La Jolla, California).

The only documented report of $K$. sima in the Central American Caribbean region is the one of Palacios-Alfaro (2009) from Costa Rica. Distributional maps of the species in the Caribbean, and in particular in Central America, occurrence gaps for most of the Central American countries (Palacios-Alfaro, 2009). Therefore, this report enriches the distributional information of this species and constitutes the second documented finding for the region as well as the first one for Honduras. According to Ward et al. (2001), lack of research effort in the completion of distribution mapping has led to limited information on population size in the Caribbean. Consequently, this species has been catalogued as DD (deficient data) in the red list of the International Union for Conservation of Nature (IUCN, 2010).

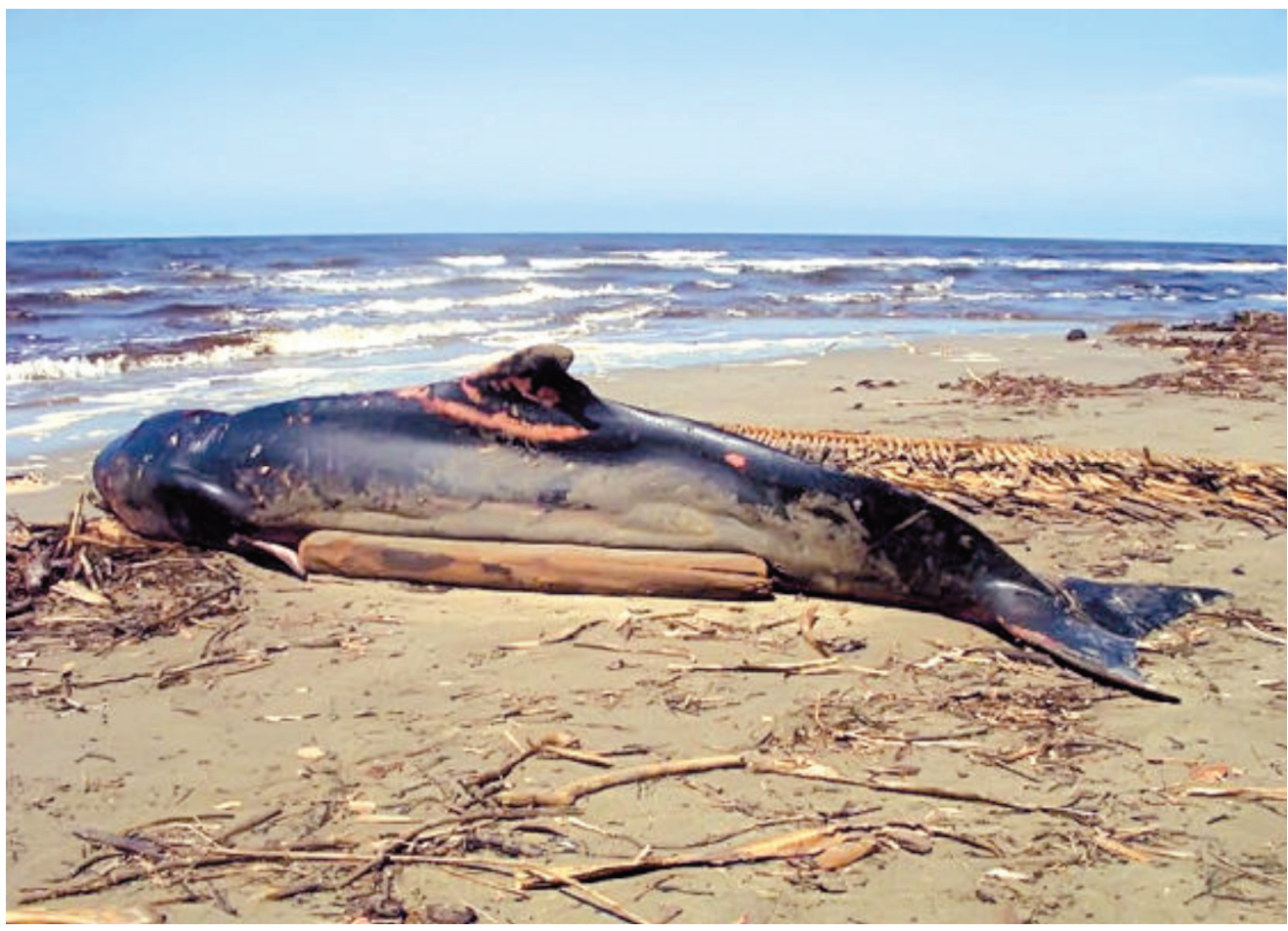

FIG. 1. K. sima stranded in Punta Izopo National Park. Entire individual depicting the position of the dorsal fin midway along the body. 


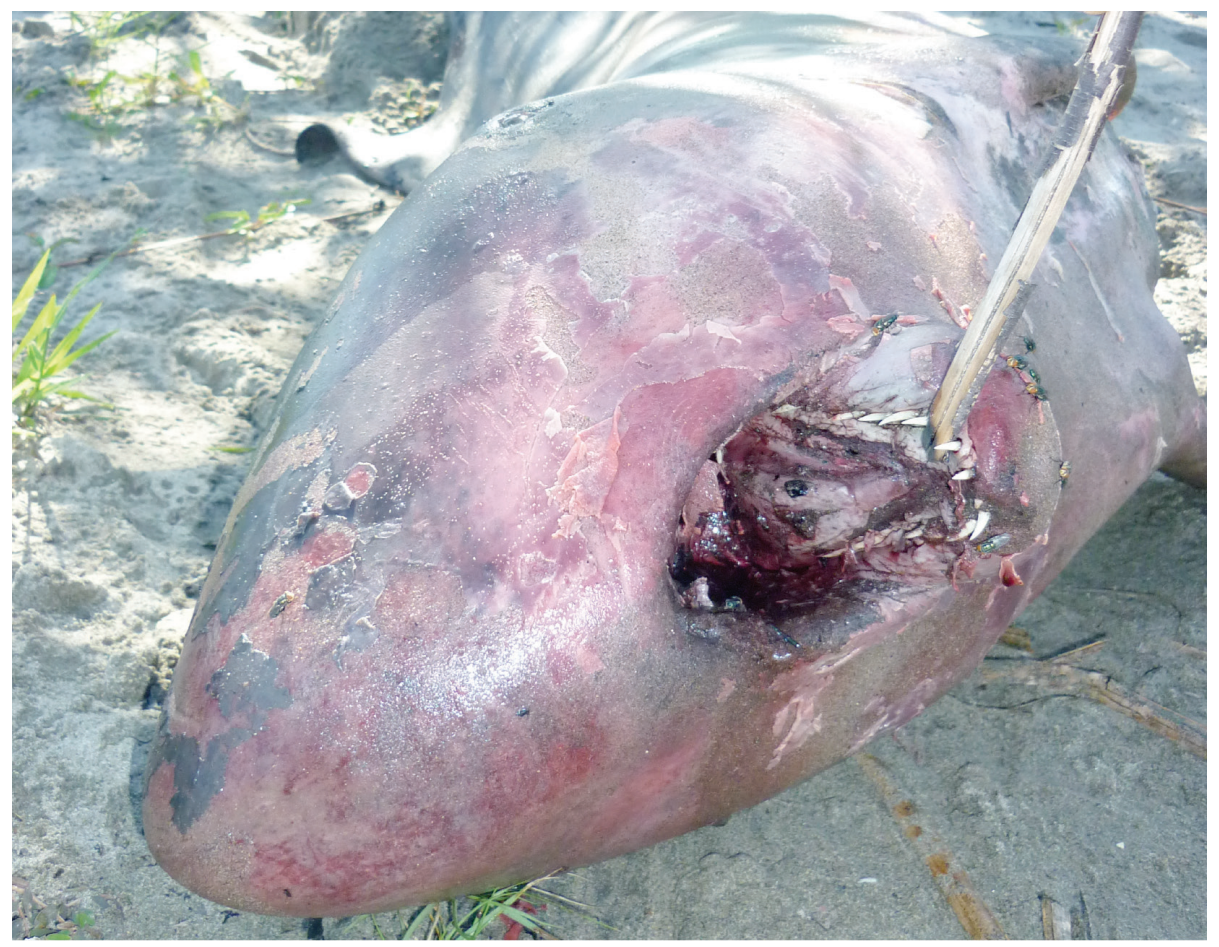

FIG. 2. K. sima teeth in both jaws.

\section{ACKNOWLEDGEMENTS}

We would like to thank Eduardo Zavala, Nelbin Bustamante and Allan Fuentes, members of the PROLANSATE Foundation for their logistics, and to the PROCORREDOR project for their support. Our gratitude to Jerry Chávez and Carlos Colón, park rangers of the Punta Izopo National Park for finding and reporting the specimen. Finally, to Hector Portillo of INCEBIO for his logistical support.

\section{REFERENCES}

Baird, R.W. (2005). Sightings of Dwarf (Kogia sima) and Pygmy (K. breviceps) Sperm Whales from the Main Hawaiian Islands. Pacific Science, 59,461-466.

Bermúdez-Villapol, L., Sayegh, A. \& León, T. (2008). Notes on the confirmation of the Dwarf sperm whale Kogia sima on Venezuelan coasts. UDO Agricola, 8,154-162.

Bolton, T., Bolton, E., Hoggard, W. \& Mullin, K. (1993). Reconocimientos aéreos de las aguas costeras del noreste de Honduras sobre mamíferos marinos y otros organismos marinos. Reporte del Instituto de Ciencias Marinas y el U.S. Marine Fisheries Service. Roatán, Honduras.
Caldwell, D.K. \& Caldwell, M.C. (1989). Pygmy Sperm Whale Kogia breviceps (de Blainville), Dwarf Sperm Whale Kogia simus (Owen, 1866). In Handbook of marine mammals: river dolphins and large toothed whales. London, England: Academic Press.

Chivers, S.J., Leduc, R.G. \& Robertson, K.M. (2005). Genetic variation of Kogia spp. with preliminary evidence for two species of Kogia sima. Marine Mammal Science, 21, 619-634.

IUCN. (2010). IUCN Red List of Threatened Species. Versión 2010.4. Retrieved from http://www.iucnredlist.org.

Jefferson, T.A., Webber, M.A. \& Pitman, R.L. (2008). Marine mammals of the world: A comprehensive guide to their identification. London, England: Academic Press/Elsevier.

Kuczaj-II, S.A. \& Yeater, D.B. (2007). Observations of roughtoothed dolphins (Steno bredanensis) off the coast of Utila, Honduras. Journal of the Marine Biological Association of the United Kingdom, 87, 141-148.

Leatherwood, S. \& Hobbs, L.J. (1988). Whales, dolphins, and porpoises of the eastern North Pacific and adjacent Arctic waters: a guide to their identification. Seattle, USA: Dover Publications.

Leatherwood, S \& Reeves, R.R. (1983). The Sierra Club Handbook of whales and dolphins. San Francisco, USA: Sierra Club Books. 
Magileviciute, E. (2007). Whales and Dolphins in Utila, Bay Islands, Honduras: preliminary observations. A project report of the Utila Centre for Marine Ecology. Bay Islands, Honduras, Central America. Retrieved from http://utilaecology.org/dowloads.

Marineros, L. \& Martínez-Gallegos, F. (1998). Mamíferos Silvestres de Honduras. Instituto Nacional de Ambiente y DesarroIlo. INADES-PAG. Tegucigalpa, Honduras.

Palacios-Alfaro, J.D. (2009). First record of the dwarf sperm whale (Kogia sima) in Caribbean waters of Costa Rica. Latin American Journal of Aquatic Mammals, 7, 103.
Reid, F.A. (1997). A field guide to the mammals of Central America and Southeast Mexico. New York, USA: Oxford University Press.

Ward, N., Moscrop, A. \& Carlson, C. (2001). Elements for the Development of a Marine Mammal Action Plan for the Wider Caribbean: A Review of Marine Mammal Distribution. UNEP (DEC)/CAR IG.20/INF 3. 